This is an author produced version of a paper published in Facilities. This paper has been peer-reviewed but does not include the final publisher proof-corrections or journal pagination.

Citation for the published paper:

Palm, Peter. (2016). Information for Decision-making in In-house and Outsourced Real Estate Management Organisations. Facilities, vol. 34, issue $13 / 14$, p. null

URL: https://doi.org/10.1108/F-05-2015-0034

Publisher: Emerald

This document has been downloaded from MUEP (https://muep.mah.se) / DIVA (https://mau.diva-portal.org). 


\title{
Information for Decision-making in In-house and Outsourced Real Estate Management Organisations
}

\author{
Peter Palm \\ Senior lecturer \\ Urban studies \\ Malmö University \\ 20506 Malmö \\ Sweden \\ peter.palm@mah.se
}

\begin{abstract}
Purpose - The aim is to examine how the real estate owner (decisionmaker) ensures being able to make informed decisions and how they differs according to organisational form.

Design/methodology/approach - This research is based on an interview study of nineteen firm representatives, six decisionmakers and thirteen management representatives, all from Swedish commercial real estate sector.

Findings - The study conclude that, regardless of organisational setting, the industry have a plan regarding handling information. The decisionmakers have all secured themselves access to required/desired information. How this is done and what kind of information it is however differ if the real estate management is in-house or outsourced. Furthermore a clear focus on financial and contractual information is evident in both organisational settings.

Research limitations/implications - The research in this paper is limited to Swedish commercial real estate sector

Practical implications - The insight the paper provides regarding required information can shed light on how information systems are built and how to improve your information sharing.

Originality/value - It provides an insight regarding how the industry, depending on organisation setting, prioritise different information and how the decisionmaker secures access to it.

Keywords - Real Estate Management, Information, Decision making, Commercial Real Estate,

\section{Introduction}

In recent years, a growing question regarding the gathering of information in organisations has been evolving. Agerwal and Hauswald (2010) argue that one of the fastest growing problems in organisations is the lack of essential information to make informed strategic decisions. This closely relates to the arguments of Milgrom and Roberts (1986) who state that a common problem decision makers face is the need to rely on information provided by individuals who are affected by their decisions. McCarty et al. (2006) also concluded this in their study 'Transforming CRE Value Through Relationship Management', wherein they consider information to be a critical success factor in real estate management.
\end{abstract}


Current research within the real estate industry indicates poorly developed strategies for knowledge and information sharing. For example, Fong and Lee (2009) conclude that no formal strategies regarding knowledge sharing and information gathering in firms currently exist, a conclusion that is supported by Pemsel and Blomé (2011). This lack of strategies should be seen in the light of Choo et al.'s (2008) conclusion that knowledge and information, which contributes to a firm's core business, should be treated just as any other irreplaceable asset. Choo et al. (2008) have shown this in research involving three cases and how they can be applied to other industries.

When considering the real estate industry, what information should contribute to the industry's core business? From the standard academic textbooks by Ling and Archer (2010) and Larsen, (2003) to the current research literature (see for example Blomé, 2010; or Abdullah et al., 2011), we know that requested information relates both to the buildings and the tenants and that both are essential for the core business of real estate companies.

In this article, the question of how the decision maker working for commercial real estate companies keeps informed when relying on one or more interested parties to provide information for making an informed decision is examined. In particular, the question of what information is requested from top management and how it is reported and studied. The aim of the article is to examine how the decision makers ensure being able to make informed decisions and how they differ according to type of organisation, as the real estate industry in Sweden organises their real estate management into two basic forms. The first form is in-house management, where the decision maker primarily deals with information reported within the company. The second form concerns outsourced management companies, where the decision maker deals with information reported from an outside party.

This article presents the results of an interview study consisting of six companies that own real estate (three with in-house management and three with outsourced management) and their management organisations in Sweden. The purpose of this article is to investigate and identify what kinds of information are requested and what information is reported to the decision makers in firms owning real estate, depending on organisational structures. The main contribution is how decision makers in companies owning real estate have regulated and built incentives to secure information for decision-making and how this varies depending on in-house or outsourced real estate management.

\section{Theoretical background}

This section consists of three parts which outline areas of interest for this paper: business-tobusiness information, information in the context of real-estate management, and the concept of incentives for information sharing.

\subsection{Information in business-to-business relationships}

Information regarding customers in a business-to-business relationship is the most complex type of information for an organisation to gather and evaluate (Davenport et al., 2001). The complexity is because customer information is derived from multiple sources within and outside of the customer's company, and its conditions can change instantly (Mithas et al., 2005). One additional factor which makes customer information complex is that within the businessto-business context, the term 'customer' includes both a company and the people within the company. This implies that it comes from numerous sources and from different levels within the company's organisation (Rollins et al., 2012). 
Managing profitable business-to-business relationships requires a stream of information from a specific customer. This stream of collected information includes both quantitative and qualitative customer information (Rollins et al., 2012). Quantitative customer information refers to numeric information (also called 'hard' information). Examples of quantitative information can be sales histories, revenue, number of employees, etc. Qualitative customer information refers to information that is difficult or impossible to quantify (also called 'soft' or 'private' information). An example of qualitative information can be a manager's expectation of the customer's behaviour based on her/his experience with that customer.

Several researchers (see for example Rollins et al., 2012; Hertzberg et al., 2010 Berger et al., 2005; or Stein, 2002;) all acknowledge the importance of qualitative information because rigid insight of customers cannot be maintained by numbers alone; the numbers simply help to validate insights based on qualitative information.

\subsection{Information in real estate management}

Within the real-estate industry, qualitative information regarding the tenants is often required information. Aside from being hard to quantify and difficult to compare, this information is also subject to interpretation by the individual manager (Stein, 2002). Together with the increased specialisation within the real estate industry, the question of how to structure the realestate management function is raised. As a result, the real-estate owners can choose to organise their real-estate management function in two ways: they can choose to have the entire management in-house and build a real estate management division of their own, or they can choose to outsource the real-estate management (Usher, 2004). As the owner of real estate, how to organise and coordinate the real-estate management function to be able to make informed decisions is up to the individual organisation.

An agency problem may arise in communicating information regarding the customers. The individual manager will have non-verifiable information regarding the customers, information obtained through day-to-day contact with the customer. This qualitative information includes opinions that cannot easily be transmitted to a third party. Petersen (2004) concludes that this type of information must be collected in person to be fully understood/interpreted, and it is difficult to compare with other information. Several empirical studies regarding qualitative information have been undertaken, especially within the banking industry (see for example Hertzberg et al., 2010 or Berger et al., 2005;). In fact, a real-estate manager has several similarities with a loan officer in a bank. Just as a loan officer is responsible for managing the relationship with the customer in order to maintain high repayment prospects, so too must a real-estate manager be responsible for managing the relationship with the firm to maintain them as customers with consistent lease payments. That is, the loan officer is responsible for obtaining and reporting information about repayment prospects of the firm, and the real-estate manager is responsible for reporting the customers' prospect of future lease agreements.

However, the similarities go even further as both professions, by authority, have the power to make financial decisions, which tie their principals to long-term commitments. When we consider a loan officer in a bank, she/he acts as the agent for the bank (principal) when approving or refinancing a loan for a client (in the client situation, she/he is the principal and the client the agent). In the bank-bank-officer relationship, the bank officer has private, sometimes tacit, knowledge of the client and is able to make decisions that in turn have longterm effects for the bank. The same goes for the real-estate manager in the leasing situation. In her/his relationship with the owner/landlord, she/he is the agent and possesses private, also 
sometimes tacit, knowledge of the tenant or the future tenant. Moreover, the decisions the realestate manager makes have long-term consequences for the firm she/he works for. Taking everything into consideration, both parties have long, extensive rights in the decision-making process, and many of their decisions are made from private, or even tacit, knowledge that is hard or almost impossible to quantify or transfer to a third party; in these scenarios, the third party refers to the bank or the real estate owner.

The questions regarding the decisions dealt with by the decision maker relates to what Abdullah et al. (2011) categorise as long-term objectives. It is, more or less, the objectives of long-term strategic decisions to optimise property value and to decide to invest, purchase or sell a property. Other decisions that relate more to the daily care of the property and its customers are handled on the real-estate-management level instead (Blomé 2010 and Lindholm and Nenonen 2006).

\subsection{Incentives for information sharing}

The most popular model of incentive contracting which attempts to explain how individuals are motivated to perform or share information is probably the classic principal-agent model. In this model, the principal cannot perfectly monitor the agent who might behave in an opportunistic manner at the expense of the principal (see for example Eisenhardt, 1989a or Williamson, 1975;). This opportunistic behaviour is described as the 'moral hazard problem'. In the realestate manger's everyday work, the real-estate owner has monitoring problems at the same time as the individual manager is responsible for large values. There is a risk of opportunistic behaviour in the sense that information that cannot be quantified is neglected in favour of observable or quantitative information.

Several experimental studies within the field of incentives and information have been conducted. The main focus of these studies has been on effort choices in terms of how to enforce co-workers to perform (see for example Coletti et al., 2005 or Towry, 2003). That is, incentives for production tasks (see for example Guthrie and Hollensbe, 2004 or Fisher et al., 2003) have been studied to a larger extent, but there has been less focus on the information exchange process for decision-making. On the other hand, Kelly (2010) did an experimental study wherein information sharing for decision making was studied in the situation of either individual or group incentives or flat-wage compensation. The conclusion from Kelly's (2010) study was that a flat wage gives the best incentive for information exchange and better quality of decisions in turn. While those with individual incentives did outperform those with group incentives, the experiment did not take trust or reputation into account, nor was it a repeated game. This could influence the result in a way that, given the knowledge of your reputation or that you will continue to do business together, may influence you to make different decisions.

Gibler and Black (2004) add another circumstance to the incentive problem: when real-estate management is outsourced. The firm hiring an outside service provider often has little knowledge regarding the service required. In that case, the service provider is the one with specialist knowledge, and a case of information asymmetry regarding the real estate managers (agents) tasks arises as well. This gives us the situation for communication as displayed in Figure I. 


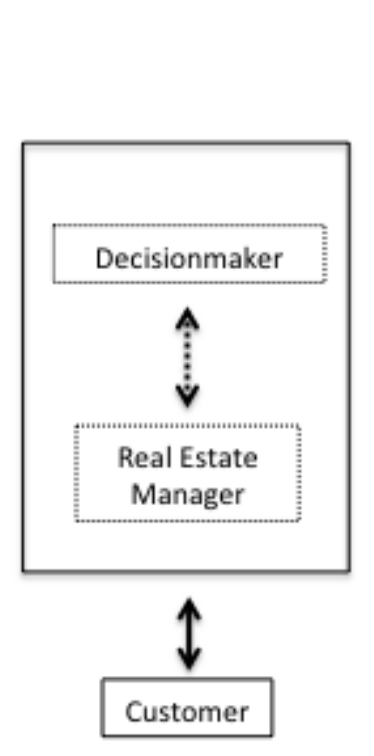

In-house management

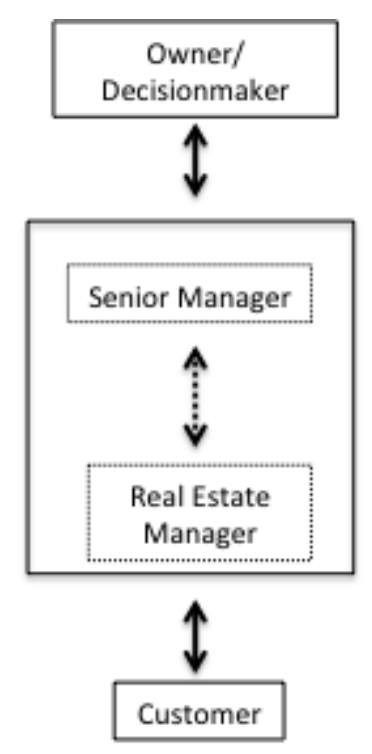

Outsourced management

Figure I. Information exchange related to property management organisational structure

In Figure I, there are a clear distinctions between information exchange in the case where the organisation is structured with in-house management and the one in which the management is outsourced. It adds one more link in the information exchange whereby information must be transported between different organisations. As Gibler and Black (2004) state, this is just one more dimension of the principal and agent complex of problems.

\section{Research design and methodology}

The basis of this article is an interview study conducted in 2014. The concern of the study was to identify how decision makers have insured the process of obtaining crucial information to make informed decisions. This has been studied by interviewing both the representatives of real-estate owners and the management teams and by examining the decision makers' view regarding the information they prioritise and consider important for decision making while, at the same time, investigating the management teams' perception of the decision makers' requirements and the management teams' incentives to share information.

\subsection{Data collection}

A selection of six real-estate owning companies (three with in-house management and three with outsourced management) were selected for the study. This selection of real-estate owning companies was completed with three companies acting as service partners for the three companies with outsourced management; thus, a total of nine companies were selected. This selection was made, as defined by Patton (2002) and Eisenhardts (1989b), through a stratified, purposeful sampling. All the companies included in the study are larger companies with the ability to have an in-house real-estate management organisation. This choice was deliberately made to ensure the same basic conditions regarding the ability to organise the management. Furthermore, a limitation on what real estate the companies own was also made. All the 
companies have their focus on the commercial real-estate market, which ensures that all companies work in a competitive market without the kind of regulation that occurs in the housing market.

The three companies with in-house management are two domestic, institutionally owned companies with regional offices in Malmö and head offices in Stockholm and one listed company with its head office in Malmö. They are all large companies in the region with a clear, outspoken focus on office premises. The three companies with outsourced management are two domestic, institutionally owned companies with their real-estate divisions based in Stockholm and one international, institutionally owned company with its regional office in Malmö. They are all large companies in the region, also with a clear, outspoken focus on office premises. The three service-providing companies are all large companies: two have international ownership and one is Swedish. Two of the companies have contract-negotiating authority at the regional office in Malmö, and the third has it centralised in Stockholm.

With every real-estate owning company, the decision makers were identified and chosen for the companies with an in-house management organisation and the head of management together with the manager/managers within the organisation. The same procedure was applied for the service-partner companies, but with the added criteria that the management team members should all work with the same partner and thereby be under the same contract. This was to ensure that the study would describe the requesting and reporting of information within the same organisational and contractual setting.

Before the interview study was conducted, a test study was initiated with one real estate-owning company and one service-partner company. This was done to be able to test the questioner, evaluate the structure of the interview study, and get a feeling of the field before conducting the interview study. In the end, the real-estate owning company was excluded from the study due to internal reorganisation within the company.

Table I. Included respondents

\begin{tabular}{|l|c|c|c|}
\hline & Decision makers & Managers & \\
\hline In-house & 3 & 6 & 9 \\
\hline Outsourced & 3 & 7 & 10 \\
\hline & 6 & 13 & 19 \\
\hline
\end{tabular}

The interviews with the nineteen firm representatives (six decision makers and thirteen management representatives) were conducted during the spring and summer of 2014. The design of the interview process was structured as semi-structured interviews (Kvale, 1995). The interviews with the decision makers from the real-estate owners had as their starting point the choice of whether or not to structure the real-estate management in-house or to outsource it. As for the interviews with the individuals from the real-estate management teams, the starting point was a more comprehensive question regarding work tasks and the representatives' placement in the organisation, in order to become familiar with the representatives' authorities.

The next theme for the interviews was information sharing. How is it reported-what are automate, in written, oral - and how is it documented and shared in the organisation? During the interviews with the decision makers, the focus was on the purpose and use, while during the interviews with the management organisation, the focus was, instead, on the reporting and documenting procedure in itself. 
The third theme regarded regulations of information sharing. How is it stipulated, and how and why is it or is it not regulated through contracts or assignments? The last theme was more open as the respondents were asked to elaborate on their experiences of information sharing in the organisation.

\subsection{Data analysis}

To enable the sorting, interpreting, classifying, and coding of the material, all interviews were taped, and the interviewer transcribed all of the material. This is a time-consuming procedure, but enables a better overall understanding and feeling for the nuances of the material. Further, it helps secure the process and ensure the respondents are correctly quoted. Taping and transcribing are also working procedures that are considered essential when working with interviews (see for example Riessman, 1993).

To enable analysis, each real-estate owner and management team pair was considered separately before clustering the three with in-house management as one and the three with outsourced management as another. This enabled what Eisenhardt (1989b) labels 'cross-case patterns'. From there, structures and similarities were crystallised as well as making it possible to highlight differences within the material. Using the framework of transaction costs for analysing the interview context in relation to incentives.

\section{Findings}

This section is divided into three parts: first, the information the decision makers request is presented, second, the information the management reports is outlined, and third, the regulations for information sharing are outlined. Moreover, each of the three subheadings are divided into two: findings within the in-house management setting is displayed before the findings within the outsourced-management setting.

\subsection{The Decision maker's perspective}

What kind of information do the decision makers request? And do decision makers with inhouse management request different information than the decision makers with outsourced management? This section is divided into two sections: the information required in the in-house situation is outlined before information required in the outsourced situation is outlined.

\section{In-house management}

The decision makers with in-house management gave a somewhat comprehensive picture of what information they require from the management organisation. Generally, the decision maker requests three types of information regarding daily business. First, it concerns the contractual status: What leases are expiring, and what new leases have been signed? This information can be obtained electronically in a CRM system, where all customers are logged with full contract information and so on. The second type of information concerns accountancy. Every quarter is reported, and the decision maker is able to both monitor and follow-up the budget electronically. However, all respondents state that both these questions of contractual status and accountancy are also a matter of follow-up in person. The third type concerns market information: What is going on out there, and how does it affect our customers and us? These are questions that are discussed in person on a regular basis and reported/discussed with the decision maker during follow-up meetings. These follow-up meetings, in which all three types of information are discussed, are held both as scheduled meetings and spontaneously. However, one common factor, regardless of whether or not the meeting is scheduled, is that they are informal, with no documentation. One managing director states the following: 
We have special electronically obtained reports for those two areas [leases and finances], but then we have at least a couple of occasions a week when I talk to them to get to know what is going on. It can be politics, or it can be anything that concerns the market and may be relevant for what we are doing. But that is spoken information. So there are no written reports or anything on this. They just talk about what is going on right now, and I met this or that person, and they might need to expand a bit, and I have considered doing it like this and so on. I do this regularly, maybe a couple of times every week, mostly by phone. Then, I phone them [regional managers], or him in Malmö we will sit down in a room and talk it through. Then we have a regularly scheduled meeting every six weeks where we sit down and go through the different problems. What shall we now do? We have real estate that is empty and has been for quite a long time now. Can't we address it in a particular way? And then we discuss this issue, and you seek influences this way.

(Managing Director, Owning and managing company)

The quotation above pinpoints the request of contractual and financial information together with market information. This indicates a rigid interest for the contractual status. It also shows that the system allows the decision maker to keep informed in this matter electronically though their business system. The information obtained orally indicates informal information sharing where the managing director seems to have a non-authoritarian relationship with the employees. For example, scheduled meetings are seldom arranged; instead, the managing director does it over the phone.

To complete the picture regarding requested information from the decision maker is a matter of information before investment. None of the three companies have any standardised forms or guidelines regarding information for investment decisions. One of the managing directors states that the question regarding guidelines has been raised before, but he prefers a more open procedure, telling his co-workers to give him all information that they themselves would have wanted in that particular case, knowing this might change on case-by-case basis. This statement from the managing director indicates a somewhat informal process with a great deal of trust for the individual real-estate manager.

Outsourced management

There was a clear view of what information the real-estate owning companies requested. They all have a strategic document for each unit of real estate wherein the real-estate owning company has outlined the long-term aims of that particular real-estate unit. That document constitutes the plan for the individual real-estate unit and is closely tied to the budget, which also is on an individual real-estate level. This document, along with the budget, is followed-up every month and then more in-depth each quarter. Before every monthly follow-up, the realestate manager from the service-partner company creates a written report, or manager report, where the budget is closely checked in accordance with outcome and deviations from the budget are commented on. During the follow-up meetings, this document is then discussed to enable a better picture which the decision maker can use to make new decisions. A written report is made after the follow-up meeting. In all three cases, this package of reports and meeting structure is set in the contract. 
All in all, the information process indicates a rigid process wherein instructions, as well as information sharing, is in writing. It also states that they have scheduled meetings that are complementary to the written reports. This also indicates that there is a well thought through process of how the information sharing should be done to make informed decisions. Much focus lies within contractual and financial information: information that is reported in writing every month with a scheduled meeting and also in a more extensive manner every quarter.

The six decision makers from both in-house and outsourced settings all gave a comprehensive picture regarding what information they require. They all request information regarding the contractual settings, with a focus on leases, and follow-up on the financials. However, it is only in the in-house setting that the decision maker requests market information from the management. The next question regards what the management organisation reports.

\subsection{The management organisation perspective}

What kinds of information is reported by the management organisation? And does in-house management report different information than outsourced management? This section is divided in two sections wherein information reported in the in-house situation is outlined before information reported in the outsourced situation is outlined.

\section{In-house management}

In the in-house setting, there is a relatively open dialogue within the organisation regarding what is going on; for example, scheduled meetings focus on contractual issues, budget followups, and market information. However, even if meetings are scheduled, no formal protocols are made. One real-estate manager stated that she takes notes during the meetings, but only for her own personal reference. This confirms the information request (as described previously by the decision maker) as a rather informal process.

Outsourced management

From the outsourcing setting, one of the heads of real estate describes the process as follows:

Most of the information we report is numbers. It is yields that we shall deliver, and those are numbers. We have standardised documents that we use with information regarding vacancies and, foremost, a complete follow-up, down to the level of each separate account for every property and how the finances are doing. This we deliver monthly. Then we also make comments in the reports regarding what has happened in the different properties. ... Most of these reports are standardised, and the focus is on the financial outcome for that month and the vacancies.

(Head of Real Estate, Service partner company)

The quotation above confirms the request of written monthly financial reports from the real estate-owning company. The respondents from the service-partner company both confirm the information reporting system and emphasise that the focus lies on numbers in terms of budget follow-up. From the statement of the real-estate manager, it is clear that this is a strict process and that the information reported is to be related to the budget and commented on according to that.

From the different management settings, the individual real-estate managers show a distinction between in-house and outsourced management regarding the reported information. In the in- 
house setting, more information sharing is conducted verbally and in a more informal process, while in the outsourced setting, it is in writing, and the process is formalised.

\subsection{Regulations for information sharing}

How do the different parties see the information sharing process, and what kinds of regulations are there in these two organisational settings?

\section{In-house management}

From the interviews, a genuine interest in the managers everyday work from the decision makers' side is observed. All of the decision makers interviewed display an interest not only in the outcome from the management in terms of leases and revenue, but also they want to be updated regarding everyday work no matter how large or small. Only one of the three included companies has monthly scheduled meetings where all the co-workers are expected to participate. The purpose of these large monthly meetings is information sharing so that everyone within the organisation has the same company information. The other two companies do not hold these kinds of meetings; instead, they relay company information by e-mail.

Furthermore, none of the included companies have any formalised information sharing from the real-estate management except for the economy system and leasing system. Instead, the decision maker keeps informed by being present among the real-estate managers and coworkers. Interesting to note is that two out of the three included companies have an open office arrangement where the decision maker is seated next to the real-estate managers. This definitely streamlines the information sharing because, although they are three of the larger real-estate companies in Sweden, the number of co-workers is rather small. Further, none of the included companies have any forum for good examples, where the real estate managers can share their experiences between each other.

Outsourced management

In the outsourced setting, one of the heads of real estate from one of the service partner companies summarised what all of the respondents in this kind of setting have exposed:

Much of the information that we are to deliver is stipulated in the contracts. It is back to what the customer wants. And that is the challenge when you work with different customers instead of in a real estate-owning company where you all want the same thing. That is not always the question here. We have to read what the customer wants. And the contract, with its appendix, tells us about the level of ambition they have and how much effort you should put into it. Do they want to be market leader? Or, what do they want? ... How much money are they willing to spend? That pretty much sets the agenda. But reporting is standardised, and it is foremost the financial outcome and how the leasing looks this month or quarter that they want to be informed about.

(Head of Real Estate, Service partner company)

This quotation highlights that the information sharing is already stipulated in the contracts between the firms and that the focus lies on numbers regarding financial outcome and leases.

One can show information sharing in the two organisational settings by what information has been gathered, how (procedure) it is reported, and what regulations exist.

Table II. Information sharing in the different organisational settings 


\begin{tabular}{|l|l|l|}
\hline & In-house management & Outsourced management \\
\hline Information reported & $\begin{array}{l}\text { Finance } \\
\text { Leases } \\
\text { Customers } \\
\text { Market }\end{array}$ & $\begin{array}{l}\text { Finance } \\
\text { Leases }\end{array}$ \\
\hline Procedure & $\begin{array}{l}\text { Electronically } \\
\text { Meetings (formal and } \\
\text { informal) }\end{array}$ & $\begin{array}{l}\text { Electronically } \\
\text { Written reports } \\
\text { Formal meetings }\end{array}$ \\
\hline Regulations & Freedom with responsibility & Contractual regulations \\
\hline
\end{tabular}

In Table II, we can see that the decision makers in both organisational settings ensure they have the information reported regarding finances and leases. In these cases, there are no differences regarding the organisational setting, but in the in-house setting, there is also information reported regarding customers and the surrounding market.

Information can be shared in three ways: electronically, in written reports, and orally. We can see from Table I that decision makers in the in-house setting keep informed by taking in information electronically through their systems and also spoken in meetings, whether they be formal (scheduled) or informal (by the coffee machine). In the outsourced setting, the decision maker also relies not only on electronic information and formal meetings but also on written reports. In the outsourced setting, no informal meetings provide information for the decision maker given that the decision maker and the management organisation providing her/him with information are not located in the same premises, and perhaps not even in the same part of the country.

The regulation of the information sharing is by "freedom with responsibility" in the in-house setting and through special sections in the contract in the outsourced setting.

\section{Discussion}

The literature on real-estate management portrays two ways of organising real-estate management: in-house or outsourced. Palm (2013) concludes that both seem to work satisfactorily for all parties concerned; it is simply a case of two different ways to organise. However, these two ways of organising both have implications. One of them is how the decision maker secures the information flow to enable informed decisions. In the in-house setting, the decision maker relies on information from interested parties, but primarily generated from her own organisation. In contrast, in the outsourced setting, the decision maker not only relies on information reported from an interested party, but the informant is also from a third party with its own agenda. The question is how the decision makers in the two organisational settings ensure the ability to make informed decisions.

The in-house setting

In the in-house organisational setting, the decision maker primarily requests tenant and market information. The economic information is automatically generated and can be easily accessed. The information flow is concentrated on market information and how the company can act to optimise and meet the tenants' expectations. Much information is available electronically, such as budgets, financial reports, lists of contracts, and contractual information; regarding this, the decision makers ensure they are up to date regarding complementary information by informal 
meetings or get-togethers. The fact that the decision maker wants the real-estate manager to act as if it is her/his own real estate - by merely stating, 'you should report all the facts you think are relevant to the case' - indicates a large degree of trust. This freedom of responsibility must act, as an incentive for information sharing for the individual real-estate manager otherwise the decision maker will not be able to make informed decisions.

The outsourced setting

The focus on the outsourced setting lies on reporting information that is to be regarded as quantitative: the number of yields, leases, and new contracts. Although researchers, such as Rolling et al., (2012) and Hintzberger et al., (2010) conclude that to be able to succeed with a customer, you need both quantitative and qualitative information-you simply cannot rely on numbers alone. However, this focus on quantitative information is in written reports and electronically atomised reports. It is during the monthly formal monthly meetings that the reports are drawn upon to get the facts behind the numbers. The representative of the real-estate owning company should have read the report in advance and be ready to discuss the reality behind the numbers.

This fairly rigid information process has advantages on all levels because everything is documented in writing. For the individual real-estate manager, this gives the benefit of never feeling on one's own; she/he will always know what is expected of her/him because the regular meetings are documented in writing. This formal structure also gives the service-partner company security; for example, in case of illness or an employee resigning, the new employee taking over the assignments will have a smoother transition period, than in an informal structure when taking over the role. This also applies for the real estate owner: they will be able to change service partner without too much hassle. Furthermore, this ability to change service partner is made easier by the real-estate owning company keeping knowledge in-house and thereby mitigating the plausible information asymmetry as proposed by Gibler and Black (2004). However, disadvantages to this method do exist. Due to the rigorous information process, the real-estate manager must spend more time writing reports and attending formal meetings, time that otherwise could have been spent on leasing or customer service.

All in all, this implies that the two organisational settings can learn from each other to minimise risks, in terms of opportunistic behaviour from the management organisation. In the in-house management situation, a more rigid information documentation could minimise the risk of opportunistic behaviour in terms of making oneself irreplaceable due to specialist knowledge that is not shared. However, the risk of ending up in a circumstance of information asymmetry, as discussed by Gibler and Black (2004) is present with in-house management. This risk is also related to Kelly's (2010) findings, which show that incentives are tied to information sharing, which is not the case in the in-house setting. In the outsourced setting, there are also no individual incentives for information sharing. Instead, it is regulated in the contracts what information is supposed to be reported, but this is not the case in the in-house setting. However, in the outsourced setting, by adding trust and a large degree of freedom with responsibility for the service-partner firm and their real-estate managers, a collaboration close to a strategic alliance is reached.

\section{Conclusions}

As discussed previously, advantages and disadvantages regarding both ways of organising can be found for the decision maker to make informed decisions. These are summarised below: 
Table III Advantages and disadvantages

\begin{tabular}{|c|c|c|}
\hline & Advantages & Disadvantages \\
\hline In-house & $\begin{array}{ll}\text { - } & \text { Informal process } \\
\text { - } & \text { Short decision paths } \\
\text { - } & \text { Focus on both hard } \\
& \text { and soft information }\end{array}$ & $\begin{array}{l}\text { Not that well } \\
\text { documented } \\
\text { - No guidelines }\end{array}$ \\
\hline Outsourced & $\begin{array}{ll}\text { - } & \text { Rigid process } \\
\text { - } & \text { Well documented }\end{array}$ & $\begin{array}{ll}\text { - } & \text { Long decision paths } \\
\text { - } & \text { Administration heavy }\end{array}$ \\
\hline
\end{tabular}

In the outsourced setting, there is, without question, a focus on hard information in terms of finances and leases. Moreover, information reporting is formal with reports in writing and in formal meetings. In the in-house setting, the decision maker also requires hard information in terms of finances and leases, but they also request soft information, such as customer and market information. The reporting is not as formal as the outsourced setting; instead of reports in writing, information sharing is conducted at the coffee machine. This implies shorter decision paths than in the in-house setting, as the real-estate manager tends to talk directly to the head of real estate to get the go-ahead decision instead of being forced to write a report before the real-estate owner representative makes a decision.

Another conclusion regarding required information is that, aside from information of tenants and financials (as stated by Ling and Archer, 2010, Blomé 2010), the decision maker also requires market information. In fact, information about the buildings is not as prioritised by the decision makers, which is in sharp contrast to the existing literature, especially the standard academic textbooks.

Given that the decision maker in the outsourced setting appears to focus on hard data in contrast to the in-house setting where the decision maker focuses both on hard data and soft information, this should give the decision maker in the in-house setting a more nuanced picture before making decisions. However, while the informal reporting in the in-house setting can render shorter decision paths, at the same time, it makes the organisation vulnerable. Given that much of the information is not written, the organisation faces a risk if someone in the organisation becomes ill or decides to quit. In contrast, the outsourced organisation does not face the same risk, as all the information is available in written reports.

A comprehensive conclusion is that the reporting of information in the two organisational settings can be improved to ensure the decision maker can make informed decisions. The decision maker in the outsourced setting can choose to develop a more relational collaboration with the service-providing company, building an alliance based on mutual trust. On the other hand, the decision maker in the in-house setting would need to develop more rigid routines mitigating opportunistic behaviour from the management organisation. However, this most be done without intruding on the managers' perception of the freedom in their responsibilities that seems to be a driving force behind the performance in the in-house setting.

However, regardless of organisational setting, all the companies included in the study have a plan regarding information sharing. The decision makers have all secured themselves access to required/desired information. This is in contrast to both Fong and Lee's (2009) and Pemsel and Blomé's (2011) conclusion that companies do not have strategies for information gathering. On the contrary, it is clear that the companies do treat financial and tenant information as an irreplaceable asset, as proposed by Choo et al. (2008). 


\section{Implications for further research}

The result of the study raises the question regarding how the customer and tenant experience the decision-making process. Do they consider in-house decision making to be more flexible and with shorter decision paths than in outsourced settings? Or do the customer and tenant perceive the decision-making process in the outsourced setting as more rigorous and well documented and thereby preferable? In this context, it would be interesting to make a case study with tenants that have experiences from organisational settings, perhaps where the real estate has been sold and the management has been altered.

\section{References}

Abdullah, S., Arman, A.R., and Abd Hamid, K.P. (2011), The characteristics of real estate assets management practice in the Malaysian Federal Government, Journal of Corporate Real Estate, Vol. 13 No. 1, pp. 16-35.

Agerwal, S., and Hauswald, R. (2010), Distance and Private Information in Lending, Review of Financial Studies Vol. 23, No. 7, pp. 27757-2788.

Berger, A.N., Miller, N.H., Petersen, M.A., Rajan, R.G. and Stein, J.C. (2005), Does function follow organizational form? Evidence from the lending practices of large and small banks, Journal of Financial Economics, No. 76, pp. 237-269.

Blomé, G. (2010), Local housing administrative models for large housing estates, Property management, Vol. 28 No. 5, pp. 320-338.

Choo, C., Wei, Bergeron, P., Detlor, B., and Heton, L. (2008), Information Culture and Information Use: An exploratory Study of three organizations, Journal of the American Society For Information Science and Technology, Vol. 59, Iss. 5, pp. 1-13.

Coletti, A.L., Sedatole, K.L., and Towry, K.L. (2005), The effect of Control Systems on Trust and Cooperation in Collaborative Environments, The Accounting Review, Vol. 80, No. 2, pp. 477-500.

Davenport, T., Harris, J., Kohli, A. (2001), How do they know their customers so well, Sloan Management Review, Vol. 42, Iss. 2, pp. 63-73.

Eisenhardt, K. (1989a), Agency Theory: An Assessment and Review, The Academy of Management Review, Vol. 14, No.1, pp. 57-74.

Eisenhardts, K. (1989b), Building theories from case study research. Academy of management review, Vol. 14. No 4, pp. 532-550.

Fisher, J.G., Peffer, S.A., and Sprinkle, G.B. (2003), Budget-Based Contracts, Budget Levels, and Group Performance, Journal of management accounting research, Vol. 15, pp. 71-94.

Fong, P.S.W., and Lee, H.F. (2009), Acquisition, reuse and sharing of knowledge in property management firms, Facilities, Vol. 27, No. 7/8, pp. 291-314.

Gibler, K.M., Black, R.T. (2004), Agency risks in Outsourcing Corporate Real Estate Functions, The journal of Real Estate Research, Vol. 26, No. 2, pp. 137-160.

Guthrie, J.P., and Hollensbe, E.C. (2004), Group incentives and Performance: A Study of Spontaneous Goal Setting, Goal Choice and Commitment, Journal of Management, Vol. 30, No. 2, pp. 263-284.

Hertzberg, A., Liberti, J.M., and Paravisini, D. (2010), Information and incentives inside the firm: Evidence from loan officer rotation, The journal of finance, Vol. 65, Iss. 3, pp. 795-828. Kelly, K., (2010), The Effects on Incentives on Information Exchange and Decision Quality in Groups, Behavioral Research in Accounting, Vol. 22, Nop. 1, pp. 43-65.

Kvale, S.. (1995), Den kvalitative forskningsintervjun. Studentlitteratur, Lund.

Larsen, James, E. (2003), Core Concepts of Real Estate Principles and Practices, Wiley \& sons Inc., New York. 
Lindholm, A.L., and Nenonen, S. (2006), A conceptual framework of CREM performance measurement tools, Journal of Corporate Real Estate, Vol. 8, No. 3, pp. 108-119.

Ling, D.C. and Archer, W.R. (2010), Real estate principles: a value approach, 3 ed., Boston , McGraw-Hill Irwing.

McCarty, T.D., Hunt, R., and Truhan, J.E. (2006), Transforming CRE value through relationship management, Journal of Corporate Real Estate, Vol. 8, Iss. 1, pp. 4-18.

Milgrom, P., Roberts, J. (1986), Relying on the information of interested parties, Rand Journal of Economics, Vol. 17, No. 1, pp. 18-32.

Mithas, S., Krishnan, M.S., and Fornell, C. (2005), Why do customer relationship management applications affect customer satisfaction, Journal of Marketing, Vol. 69, No. 4, pp. 201-209.

Palm, P. (2013), Strategies in real estate management: two strategic pathways, Property Management, Vol. 31, No. 4, pp. 311-325.

Patton, M.Q. (2002), Qualitative research \& Evaluation methods 3ed. Sage Thousand Oaks. Pemsel, S., and Blomé, G. (2011), Knowledge as a source of power in real esate organizations, CFM Nordic Conference 22-23 August 2011, Technical University of Denmark.

Petersen, M.A. (2004), Information: Hard and Soft, Working paper, Northwestern University. Riessman, C.K. (1993), Narrative analysis. Qualitative research methods series 30 SAGE University paper.

Rollins, M., Bellenger, D.N., and Johnston, W.J. (2012), Customer information utilization in business-to-business markets: Muddling through process?, Journal of Business Research No. 65 , pp. $758-764$.

Stein, J.C. (2002), Information Production and Capital Allocation: Decentralized versus Hierarchical Firms, Journal of Finance, Vol. 57, No. 5, pp. 1891-1921.

Towry, K.L. (2003), Control in a Teamwork Environment - The Impact of Social Ties on the Effectiveness of Mutual Monitoring Contracts, The Accounting Review, Vol. 78, No. 4, pp. 1069-1095.

Usher, N. (2004), Outsource or in-house facilities management: The pros and cons, Journal of Facilities Management, Vol. 2, No. 4, pp. 351-359.

Williamson, O.E. (1975), Markets and Hierarchies Analysis and Antitrust Implications. Free Press cop. New York. 